\title{
INFLUÊNCIA DO MÉTODO DE EXTRAÇÃO NO RENDIMENTO, PERFIL PROTÉICO E SOLUBILIDADE DE CONCENTRADOS PROTÉICOS DE AMARANTO
}

\author{
CATHIAREIS* \\ FLAVIA MARIANETTO**
}

Foram produzidos quatro concentrados protéicos de amaranto, variando-se as condições da etapa de extração alcalina: pH 8,0/água, pH 9,0/água, pH 8,0/ $0,4 \mathrm{M} \mathrm{NaCl}$ e pH 9/0,4 M NaCl. Os dois últimos foram dialisados após a etapa de precipitação em pH 4,5 e neutralização para eliminação do excesso de $\mathrm{NaCl}$. Foram verificadas perdas de $30-50 \%$ das proteínas nas principais etapas de obtenção do concentrado, extração em pH alcalino e precipitação no pl. Obtevese recuperação máxima de $24 \%$ quando a extração foi realizada em $\mathrm{pH}$ 9/água e mínima de $11,3 \%$ em $\mathrm{pH} 8,0$ / $0,4 \mathrm{M}$ de $\mathrm{NaCl}$. O perfil eletroforético das proteínas evidenciou que a fração com baixo peso molecular (albuminas) é extraída em maior proporção nas soluções $0,4 \mathrm{M} \mathrm{NaCl}$. O perfil das proteínas presentes no resíduo da extração alcalina mostrou-se semelhante ao dos concentrados protéicos obtidos, no entanto, os extraídos em solução salina revelaram maior proporção de frações com baixo peso molecular. A solubilidade das proteínas do concentrado protéico de amaranto dependeu do método de extração, sendo verificada maior solubilidade nas extraídas em pH 9 que em pH 8.

PALAVRAS-CHAVE: AMARANTO; PROTEÍNAS; PERFIL ELETROFORÉTICO.

\section{INTRODUÇÃO}

O amaranto, pseudocereal do gênero Amaranthus, está inserido na classe das Dicotiledôneas e na família Amaranthaceae. Não se trata de cereal, pois apresenta aspectos botânicos (como inflorescência do tipo panícula) e características nutricionais como alto teor protéico e de aminoácidos (lisina e os sulfurados).

* $\quad$ Bolsista de iniciação científica, graduanda em Engenharia de Alimentos.

** Doutora em Ciência de Alimentos, Professora do Departamento de Alimentos e Nutrição, Faculdade de Engenharia de Alimentos, Universidade de Campinas (UNICAMP), Campinas (e-mail: flavia@fea.unicamp.br). 
Tanto as folhas como os grãos do amaranto são utilizados na alimentação humana, sendo o último mais explorado economicamente (BECKER et al., 1981; IRVING, BETSCHART e SAUNDERS, 1981; SINGHAL e KULKARNI, 1988).

O interesse pelo grão de amaranto tem crescido nos últimos anos, particularmente devido à boa qualidade nutricional de suas proteínas (semelhante à da caseína) (MENDONZA e BRESSANI, 1987; BEJOSANO e CORKE, 1998) e características especiais de seu amido (JANE et al., 1992). Outro aspecto relevante em relação a esse pseudocereal é a ausência de glúten na sua composição, possibilitando seu consumo por portadores de doença celíaca (MAHAN e ARLIN, 1995; MARCíLIO et al., 2003). Tais características levaram diversos países a iniciar seu cultivo, entre os quais o Brasil. A EMBRAPA (Planaltina-DF) tem plantado amaranto em regime experimental na Região Centro-Oeste brasileira.

Apesar do alto valor nutricional das proteínas do amaranto, sua utilização como ingrediente depende grandemente de suas propriedades funcionais. Essas estão estreitamente relacionadas com suas características estruturais que por sua vez dependem das condições utilizadas no processo de extração (FIDANTSI e DOXASTAKIS, 2001; MARTINEZ e AÑÓN, 1996). As propriedades funcionais requeridas para a utilização de produtos protéicos envolvem solubilidade, absorção de água e óleo, gelificação e coagulação, entre outras (MARCONE e KAKUDA, 1999).

O amaranto contém entre 12 e 17\% de proteína e bom balanço de aminoácidos essenciais em comparação com diversos cereais (TEUTONICO e KNORR, 1985; BRESSANI e GARCIA-VELA, 1990). Suas principais frações protéicas são as albuminas, globulinas e glutelinas, que diferem em solubilidade (PAREDEZ-LÓPEZ, MORAESCOBEDO e ORDORICA-FALOMIR, 1988; SEGURA-NIETO et al., 1992; MARTINEZ e AÑÓN, 1996). A técnica utilizada para obtenção de concentrados protéicos de amaranto influi na proporção de cada fração protéica, na qualidade nutricional e em suas propriedades funcionais.

Diversas modificações do método clássico (solubilização em solução alcalina e precipitação no pl) têm sido utilizadas para obtenção de 
concentrados ou isolados de proteínas de amaranto. Os métodos compreendem a solubilização de proteínas em pH entre 7 e 11, com ou sem a adição de $\mathrm{NaCl}$ na solução e precipitação em $\mathrm{pH}$ que varia entre 2 e 5 (PAREDEZ-LÓPEZ, MORA-ESCOBEDO e ORDORICAFALOMIR, 1988; SORIANO-SANTOS, IWABUCHI E FUJIMOTO, 1992; LUQUEZ, FERNANDEZ e MUCCIARELLI, 1996; MARTINEZ e AÑÓN, 1996; FIDANTSI e DOXASTAKIS, 2001; SALCEDO et al., 2002). O teor protéico desses concentrados ou isolados varia de 32\% (FIDANTSI e DOXASTAKIS, 2002) a cerca de 90\% (MARTINEZ e AÑÓN, 1996), dependendo das condições de extração. O rendimento em proteína, importante parâmetro do processo, raramente é avaliado em estudos de obtenção de produtos protéicos do amaranto. Mesmo estudos voltados para a otimização do processo (SALCEDO-CHAVEZ et al., 2002) não estudaram essa variável. SORIANO-SANTOS e CÓRDOBASALGADO (1995) reportaram 36\% de rendimento com a succinilação prévia das proteínas. A eliminação do amido por enzimas amilolíticas foi indicada por RADOSAVLJEVIC, JANE e JOHNSON (1998) para aumentar o rendimento protéico. AULER (2002), no entanto, não observou aumento no rendimento protéico ao hidrolisar amido da farinha do amaranto para a obtenção de concentrados protéicos, o qual permaneceu na mesma faixa do concentrado sem hidrólise (em torno de $20 \%)$.

O presente trabalho teve como objetivo estudar a influência de diferentes métodos no rendimento, perfil protéico e na solubilidade de concentrados protéicos de amaranto.

\section{MATERIAL E MÉTODOS}

\subsection{MATERIAL}

Utilizou-se grão de Amaranthus cruentus, variedade Japonica, doado pela EMBRAPA Unidade Cerrado, Planaltina (DF).

\subsection{OBTENÇÃO DA FARINHA INTEGRAL DE AMARANTO}

Para a obtenção da farinha, o grão foi moído em moinho de rolos (Brabender modelo Quadrumat Senior) com umidade natural. A moagem ocorreu em duas etapas, uma de quebra e outra de redução. 
Frações foram obtidas por separação em peneiras de 599 m (40 mesh), $250 \mathrm{~m}$ (60 mesh), $150 \mathrm{~m}$ (100 mesh) e fundo. Para a obtenção do concentrado protéico de amaranto utilizou-se farinha com granulometria de $150 \mu \mathrm{m}$ (100 mesh), proveniente tanto da quebra quanto da redução (MARCíLIO et al., 2003).

\subsection{OBTENÇÃO DO CONCENTRADO PROTÉICO DEAMARANTO (CPA)}

Obteve-se o concentrado protéico da farinha integral de amaranto, mediante combinação dos métodos descritos por LUQUEZ, FERNÁNDEZ e MUCCIARELLI (1996) e MARTINEZ e AÑÓN (1996). Efetuou-se a solubilização protéica em $\mathrm{pH}$ alcalino e precipitação na região isoelétrica $(\mathrm{pH} 4,25)$ de acordo com o fluxograma descrito na Figura 1. Foram produzidos quatro concentrados, variando-se as condições da etapa de extração alcalina: CPA $1=\mathrm{pH}$ 8/água, CPA $2=\mathrm{pH}$ 9/água, $\mathrm{CPA} 3=\mathrm{pH} 8 / 0,4 \mathrm{M} \mathrm{NaCl}, \mathrm{CPA} 4=\mathrm{pH} 9 / 0,4 \mathrm{M} \mathrm{NaCl}$.

\section{FIGURA 1 - FLUXOGRAMA DE OBTENÇÃO DO ISOLADO PRO- TÉICO DE AMARANTO (IPA)}

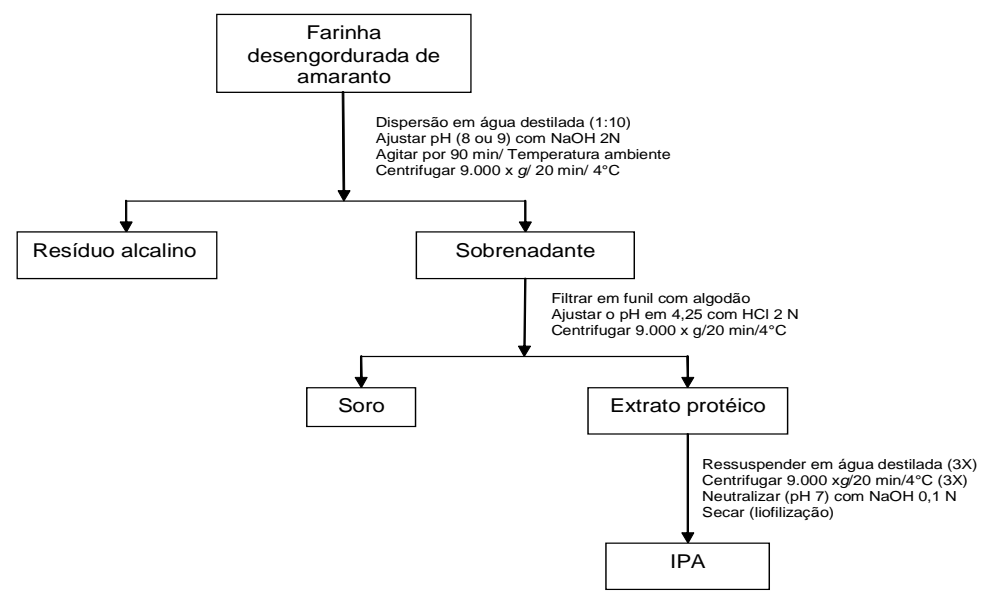

As demais etapas de obtenção do IPA ocorreram conforme o fluxograma da Figura 1. Para diminuir a concentração do sal no produto final (processos utilizando extração com solução $0,4 \mathrm{M} \mathrm{NaCl}$ ), a suspensão neutralizada foi dializada por 48 horas sob refrigeração 
antes de se proceder a liofilização do concentrado.

A recuperação ou rendimento protéico e as perdas de proteína nos resíduos da extração alcalina e precipitação isoelétrica foram calculados em relação à quantidade de proteína existente inicialmente.

\subsection{CARACTERIZAÇÃO DAFARINHA E DO CONCENTRADO DE AMARANTO}

As amostras foram analisadas quanto à umidade e cinzas, segundo a metodologia da AOAC (1990), e lipídios totais (determinado apenas para a farinha) pelo método de BLIGH e DYER (1959). Determinouse a proteína bruta pelo método semimicro Kjeldahl (AOAC, 1990). Quantificou-se a porcentagem de nitrogênio presente nas amostras, convertendo-a em proteína bruta (fator de conversão 6,25). Todas as determinações foram realizadas em triplicata.

Determinou-se o perfil das proteínas do concentrado protéico de amaranto por eletroforese em gel de poliacrilamida, contendo dodecil sulfato sódico (SDS-PAGE) de acordo com o método de LAEMMLI (1970).

A solubilidade protéica foi determinada de acordo com MORR et al. (1985) e a proteína solúvel pelo método de Kjeldahl. Determinou-se a solubilidade em solução de $\mathrm{NaCl}$ 0,1 M em pH 3,0 e 7,0. Calculou-se a solubilidade protéica conforme a equação 1 :

$$
\text { Solubilidade }(\%)=\frac{A x 50}{W x S / 100} \times 100
$$

Na qual:

$A=$ concentração de proteína no sobrenadante $(\mathrm{mg} / \mathrm{mL})$;

$W=$ peso da amostra $(\mathrm{mg})$;

$S=$ concentração de proteína na amostra (\%).

\section{RESULTADOS E DISCUSSÃO}

Foram obtidas $2280 \mathrm{~g}$ de farinha com granulometria de $150 \mu_{\mathrm{m}}(100$ 
mesh) a partir de $4000 \mathrm{~g}$ do grão da variedade Amaranthus cruentus.

A composição aproximada (\%, base seca) da farinha de amaranto apresentou 9,75 $\pm 0,05$ de umidade, 2,33 $\pm 0,02$ de cinza, 7,07 $\pm 0,05$ de lipídios totais, 15,6 \pm 0,1 de proteínas e 65,25 de carboidratos (por diferença). Valores similares para a composição do grão de amaranto foram reportadas por outros autores. BECKER et al. (1981), trabalhando com o mesmo tipo de grão (Amaranthus cruentus), obtiveram $6,71 \%$ de umidade, $2,8 \%$ de cinzas, $7,71 \%$ de lipídios e 17,55\% de proteínas. TEUTONICO e KNORR (1985) encontraram 6,23-6,71\% de umidade, 2,8-3,6\% de cinzas, 6,3-8,1\% de lipídios e 13,2-17,6\% de proteínas. AULER obteve $7,1 \%$ de umidade, $3,67 \%$ de cinzas, $6,65 \%$ de lipídios e $14,64 \%$ de proteínas.

Avaliou-se a perda de proteína nas diversas etapas do processo de extração pelo rendimento em proteína no resíduo, no soro e na água de ressuspenção (Tabela 1). No resíduo da extração alcalina houve perda de cerca de $50 \%$ de proteína em relação à quantidade inicial na farinha, evidenciando condições de processo não adequadas para alcançar boa recuperação protéica. Com adição de $\mathrm{NaCl}$, a quantidade de proteína no resíduo foi menor devido ao aumento da solubilidade das proteínas em meio com maior força iônica. SORIANO-SANTOS, IWABUCCHI e FUJIMOTO (1992) obtiveram solubilização semelhante, 48 a 51\%, utilizando soluções com 5 e $10 \%$ de $\mathrm{NaCl}$. A perda de proteína no resíduo pode resultar da interação natural das fibras, gorduras e amido com a proteína, o que dificulta sua remoção. Observou-se grande perda de proteína no soro após a precipitação no pl. Do total de proteínas solubilizadas na extração, cerca de $50 \%$ permaneceu em solução após a precipitação em pH ácido. No entanto, o pH utilizado na precipitação $(4,5)$ enquadrou-se na faixa indicada por diversos autores como sendo a de maior eficiência na precipitação das proteínas do amaranto (PAREDES-LÓPEZ, MORA-ESCOBEDO e ORDORICA-FALOMIR, 1988; MARTINEZ e AÑÓN, 1996). A precipitação mostrou-se menos eficiente ainda com extração na presença de $\mathrm{NaCl}$, que contribui para a solubilidade das proteínas nesse $\mathrm{pH}$.

Segundo MARCONE e KAKUDA (1999), a alta solubilidade das proteínas de amaranto na região do pl deve-se ao elevado grau de fosforilação e glicolisação que contribui para sua hidrofilicidade. 
O concentrado obtido em $\mathrm{pH}$ 9,0 apresentou maior porcentagem de recuperação protéica, seguido pelo concentrado com pH 8,0. Em estudo semelhante, AULER (2002) obteve $29 \%$ de recuperação protéica utilizando $\mathrm{pH}$ 8,0 na extração. PAREDES-LÓPEZ, MORAESCABEDO e ORDORICA-FALOMIR (1988) também verificaram maior rendimento com pH 9 para extração e $\mathrm{pH} 4$ para a precipitação. Valores mais elevados de $\mathrm{pH}$ na etapa de extração, em geral, resultam no aumento da porcentagem final de proteína no concentrado protéico. No entanto, pH de extração muito alto pode provocar danos irreversíveis às proteínas, como formação de lisilalanina, diminuição da digestibilidade e do valor biológico que impedem sua utilização (FINOT, 1997).

TABELA1-PORCENTAGEM DE PROTEÍNAS EM CADA SUBPRODUTO DA EXTRAÇÃO EM RELAÇÃO À QUANTIDADE INICIAL DE PROTEÍNA NA FARINHA

\begin{tabular}{|c|c|c|c|c|}
\hline & \multicolumn{4}{|c|}{ Condições de extração } \\
\hline & pH8,0/água & pH 9,0/água & $\mathrm{pH} 8,0 / 0,4 \mathrm{M} \mathrm{NaCl}$ & $\mathrm{pH} 9,0 / 0,4 \mathrm{M} \mathrm{NaCl}$ \\
\hline Resíduo & 59,4 & 51,4 & 47,2 & 47,2 \\
\hline Soro & 18,7 & 17,5 & 37,0 & 32,2 \\
\hline $\begin{array}{l}\text { Água da } \\
\text { ressuspenção }\end{array}$ & 0,9 & 0,8 & 0,6 & 1,0 \\
\hline CPA & 20,0 & 23,4 & 11,3 & 15,3 \\
\hline
\end{tabular}

Os valores representam a média de 3 diferentes extrações.

$\mathrm{CPA}=$ concentrado protéico de amaranto.

A composição química aproximada dos concentrados protéicos de amaranto está apresentada na Tabela 2. Os concentrados com adição de $\mathrm{NaCl}$, sem diálise, apresentaram conteúdo de cinzas cerca de $40 \%$ maior que os concentrados sem adição de sal. Após a diálise, os teores de cinza mostraram-se semelhantes aos dos concentrados sem adição de $\mathrm{NaCl}$. O conteúdo protéico foi similar, entre 59,8 e $62,8 \%$, para todas as condições de extração utilizadas. Teores superiores de proteína $(66,3 \%)$ foram encontrados por PAREDESLÓPES, MORA-ESCOBEDO e ORDORICA-FALOMIR (1988), 
utilizando $\mathrm{pH}$ 9,0 para a etapa de extração e $\mathrm{pH} 4$ na precipitação. SALCEDO-CHÁVEZ et al. (2002) verificaram teores entre 75,8 e 83,4\% de proteína, utilizando combinações de $\mathrm{pH}$ de extração e precipitação de 8,5/5,0 e 9/4,5, respectivamente. LUQUEZ, FERNÁNDEZ e MUCCIARELLI (1996) obtiveram concentrados com 50,9\% de proteínas, utilizando $\mathrm{pH}$ de extração 11 e de precipitação 4,5. FIDANTSI e DOXASTAKIS (2001) usaram condições mais amenas de extração (pH 10 e de precipitação 4,6), obtendo CPA com $36,0 \%$ de proteínas.

\section{TABELA 2 - CARACTERIZAÇÃO DOS CONCENTRADOS PROTÉICOS DE AMARANTO EM BASE SECA}

\begin{tabular}{ccccc}
\hline & $\begin{array}{c}\text { CPA1 } \\
(\mathrm{pH} 8,0 / \text { água })^{1}\end{array}$ & $\begin{array}{c}\text { CPA2 } \\
(\mathrm{pH} \mathrm{9,0/água})^{1}\end{array}$ & $\begin{array}{c}\text { CPA3 } \\
(\mathrm{pH} \mathrm{8,0/0,4} \mathrm{M} \mathrm{NaCl})^{1}\end{array}$ & $\begin{array}{c}\text { CPA4 } \\
(\mathrm{pH} \mathrm{9,0/0,4} \mathrm{M} \mathrm{NaCl})^{1}\end{array}$ \\
\hline Umidade & $2,02 \pm 0,04$ & $1,73 \pm 0,08$ & $3,03 \pm 0,08^{2}$ & $2,39 \pm 0,05^{2}$ \\
Cinza & $1,5 \pm 0,2$ & $1,3 \pm 0,2$ & $3,5 \pm 0,2^{3}$ & $3,2 \pm 0,4^{3}$ \\
Proteína & $\begin{array}{c}59,80 \pm \\
0,09^{\mathrm{a}}\end{array}$ & $62,7 \pm 0,8^{\mathrm{b}}$ & $60,6 \pm 0,3^{\mathrm{a}}$ & $1,14 \pm 0,01^{2}$ \\
\hline
\end{tabular}

$\mathrm{CPA}=$ concentrado protéico de amaranto.

Valores representam média de 3 repetições \pm desvio-padrão.

Valores de proteína seguidos por letras iguais na mesma linha são estatisticamente iguais pelo teste de Tuckey ( $5 \%$ de probabilidade).

${ }^{1}$ Condições de extração.

${ }^{2}$ Resultados relativos ao concentrado não-dialisado.

${ }^{3}$ Resultados relativos ao concentrado dialisado.

Os perfis eletroforéticos das proteínas dos concentrados e dos resíduos variaram em função do $\mathrm{pH}$ e da força iônica da solução de extração (Figura 2). Os CPA extraídos em solução de $\mathrm{NaCl}$ (CPA3 e CPA4) apresentaram polipeptídios na faixa e abaixo de $20 \mathrm{kDa}$ em maior proporção que os demais. Segundo MARTINEZ e AÑÓN (1996), polipeptídios nessa faixa de peso molecular correspondem às albuminas-1, assim como os polipeptídios de massa molecular intermediária (entre 30 e $60 \mathrm{kDa}$ ), que foram observadas em todos os CPA obtidos. A maior intensidade das bandas da fração albumina em soluções $0,4 \mathrm{M} \mathrm{NaCl}$ está de acordo com os resultados de PARÉDESLÓPEZ, MORA-ESCOBEDO e ORDORICA-FALOMIR (1988) que também observaram polipeptídios com peso molecular na faixa 
de 45-50 kDa (associados às frações albumina e globulina). Polipeptídios entre 53 e 56,5 kDa e com maior peso molecular, correspondentes às frações albumina-2, globulinas e glutelinas, são preferencialmente extraídas em pH 9,0 (MARTINEZ e AÑóN 1996). Polipeptídios com peso molecular em torno de 77 kDa da fração globulina (MARTINEZ e AÑóN, 1996) não foram detectados em nenhum dos CPA obtidos, possivelmente devido às condições relativamente amenas de extração.

A extração de diferentes frações pode resultar em variação na composição aminoacídica dos concentrados, pois as albuminas do amaranto são mais ricas em lisina que as demais frações enquanto as globulinas apresentam maiores concentrações de aminoácidos sulfurados (BRESSANI e GARCIA-VELA, 1990).

$\mathrm{Na}$ Figura $2 \mathrm{~b}$ observam-se (para as proteínas presentes no resíduo) perfis muito semelhantes aos encontrados para os concentrados, com exceção das bandas com baixo peso molecular. Essas bandas (presentes nos resíduos da extração em água) foram observadas nos CPA extraídos com $\mathrm{NaCl}$ (Figura 2a), indicando que tais proteínas são extraídas em ambiente com maior força iônica. Interessante notar que a precipitação isoelétrica não fez com que os perfis das proteínas do CPA diferissem substancialmente do perfil do resíduo, embora frações como a albumina -2 apresentem pl na faixa de 6,0 (MARTINEZ e AÑÓN, 1996).

Para a análise de solubilidade (Tabela 3), os concentrados protéicos que tiveram adição de $\mathrm{NaCl}$ na etapa de extração foram dialisados. $\mathrm{O}$ alto teor de sais pode afetar essa propriedade, prejudicando a comparação com os demais concentrados. Para todos os CPA, a solubilidade em $\mathrm{pH} 7$ foi ligeiramente inferior à obtida em $\mathrm{pH} 3$, com exceção do CPA2 que revelou diminuição de $40 \%$ na solubilidade com o aumento do pH. MARCONE e KAKUDA (1999) constataram para isolado de proteína de amaranto (obtido por extração em tampão fosfato $\mathrm{pH} 7,5$, sem precipitação no $\mathrm{pl}$ ) pequena variabilidade na solubilidade, 59,4 e 58,3\% em pH 3 e 7, respectivamente. Em estudo de solubilidade protéica, utilizando o mesmo método, AULER (2002) obteve para concentrado extraído em água pH 8,0 e dialisado, 52\% de solubilidade em $\mathrm{pH} 3,0$ e $45 \%$ em pH 7,0. Os CPA obtidos da extração com $0,4 \mathrm{M}$ de $\mathrm{NaCl}$ apresentaram nos dois valores de $\mathrm{pH}$ 
estudados (mais evidente no $\mathrm{pH}$ 7) solubilidade maior que os extraídos em água $(p<0,05)$. Possivelmente a fração albumina com baixo peso molecular, presente em maior proporção nos primeiros (Figura 2), contribuiu para a elevação da solubilidade. MARCONE e KAKUDA (1999) obtiveram solubilidade semelhante para as proteínas do amaranto e da soja, com exceção da região do pl em que a proteína de soja é praticamente insolúvel ( $3 \%$ de solubilidade). WANG e ZAYAS (1991), analisando o efeito do $\mathrm{pH}$ na solubilidade de concentrados de soja, obtiveram cerca de $45 \%$ de solubilidade em $\mathrm{pH} 7,0$.

\section{FIGURA 2 - PERFIL ELETROFORÉTICO DAS PROTEÍNAS (a) DOS CONCENTRADOS PROTÉICO (b) DOS RESÍDUOS DA EXTRAÇÃO}
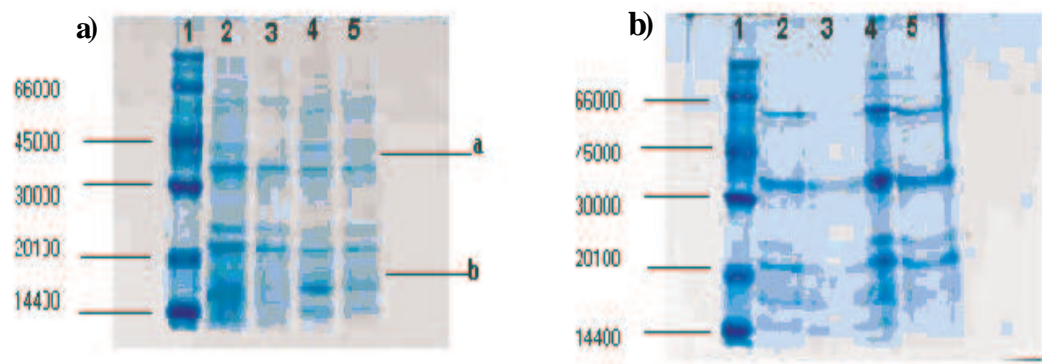

Coluna 1: padrão (fosforilase-b, $97 \mathrm{kDa}$; ovalbumina, $66 \mathrm{kDa}$; anidrase carbônica $30 \mathrm{kDa}$; inibidor de tripsina, 20,1 kDa; alfa-lactoalbumina, 14,4 kDa); Coluna 2: extração em pH 8,0; Coluna 3: extração em pH 9,0; Coluna 4: extração em pH 8.0 + 0,4 M NaCl; Coluna 5: extração em pH 9,0 + 4,0 M NaCl.

\section{TABELA 3 - SOLUBILIDADE PROTÉICA DE CONCENTRADOS DE PROTEÍNA DE AMARANTO EM PH 3,0 E 7,0}

\begin{tabular}{|c|c|c|}
\hline & \multicolumn{2}{|c|}{ Solubilidade (\%) } \\
\hline & pH 3 & p H 7 \\
\hline $\begin{array}{c}\text { CP P A 1 } \\
(\mathrm{pH} 8,0 / \text { água })\end{array}$ & $37,6 \pm 0,1^{b}$ & $36,70 \pm 0,1^{a}$ \\
\hline $\begin{array}{c}\text { C P A 2 } \\
(\mathrm{pH} 9,0 / a ́ g u a)\end{array}$ & $49,8 \pm 0,1^{a}$ & $31,7 \pm 0,1^{b}$ \\
\hline $\begin{array}{c}\text { CPA P } 1 \\
(\mathrm{pH} 8,0 / 0.4 \mathrm{M} \mathrm{N} \mathrm{a} \mathrm{I})^{1}\end{array}$ & $52,6 \pm 0,1^{a}$ & $45,8 \pm 0,1^{c}$ \\
\hline $\begin{array}{c}\text { CPA } \mathbf{P A} \\
(\mathrm{pH} \quad 9,0 / 0.4 \mathrm{M} \text { a C I })^{1}\end{array}$ & $51,6 \pm 0,1^{a}$ & $45,5 \pm 0,1^{c}$ \\
\hline
\end{tabular}

Os valores representam a média de 3 repetições \pm desvio-padrão.

Valores seguidos por letras iguais na mesma coluna são estatisticamente iguais pelo teste de Tuckey (5\% de probabilidade); ${ }^{1}$ concentrados dialisados. 


\section{CONCLUSÃO}

A extração de proteína do amaranto evidenciou perdas entre 20 e $50 \%$ nas principais etapas do processo (extração em pH alcalino e precipitação no pl), obtendo-se recuperação máxima de $24 \%$ em extração com água e $\mathrm{pH}$ 9. O perfil das proteínas presentes no resíduo da extração alcalina mostrou-se semelhante ao dos concentrados protéicos, no entanto, aqueles obtidos com extração em solução salina apresentaram maior proporção de albuminas com baixo peso molecular. A solubilidade das proteínas de amaranto em $\mathrm{pH} 3$ não dependeu das condições de extração e em pH 7, os CPA extraídos em solução salina mostraram valores ligeiramente superiores. Assim, a extração com água é mais indicada pelo aumento no rendimento em relação à solução $0,4 \mathrm{M} \mathrm{NaCl}$ e semelhança da solubilidade das proteínas.

Apesar do produto obtido apresentar concentração protéica aceitável $(60 \%)$ e boa solubilidade, o baixo rendimento do processo ( $23 \%)$ sugere a necessidade de estudos futuros para sua otimização.

\section{Abstract \\ INFLUENCE OF THE EXTRACTION METHOD ON THE YIELD, PROTEIN PROFILE AND SOLUBILITY OF AMARANTH PROTEIN CONCENTRATES}

Four amaranth protein concentrates were produced, varying the conditions of the alkaline extraction stage: $\mathrm{pH} 8.0 /$ water, $\mathrm{pH} 9.0 /$ water, $\mathrm{pH} 8.0 / 0.4 \mathrm{M} \mathrm{NaCl}$ and $\mathrm{pH}$ $9.0 / 0.4 \mathrm{M} \mathrm{NaCl}$. The last two were dialyzed after precipitation at $\mathrm{pH} 4.5$ and neutralization to eliminate the excess of $\mathrm{NaCl}$. Protein losses from 30 to $50 \%$ during the main stages of concentrate obtention, extraction in alkaline $\mathrm{pH}$ and pl precipitation. Maximum recovery of $24 \%$ was obtained when the extraction was done in $\mathrm{pH} 9.0 /$ water, and lowest value, $11.3 \%$ in $\mathrm{pH} 8.0 / 0.4 \mathrm{M} \mathrm{NaCl}$. The proteins electrophoretic profile evidenced that the fraction with low molecular mass (albumins) is extracted in higher proportion in solutions $0.4 \mathrm{M} \mathrm{NaCl}$. The residue of the alkaline extraction showed a similar protein profile to the concentrates, although those obtained in saline solution showed a greater proportion of low molecular mass fractions. The solubility of amaranth proteins in the concentrate was dependent on the extraction method, the concentrates obtained in $\mathrm{pH} 9$ showed higher solubility than those extracted in $\mathrm{pH} 8$. 
KEY-WORDS: AMARANTH; PROTEIN; ELECTROPHORETIC PROFILE.

\section{REFERÊNCIAS}

1 AOAC. Association of Official Analytical Chemists. Official Methods of AOAC International. $15^{\text {th }}$ ed. Washington, 1990.

2 AULER, F. Produção e caracterização de farinhas e concentrados protéicos de amaranto (Amaranthus cruentus). Campinas, 2002. 75 p. Dissertação (mestrado), Faculdade de Engenharia de Alimentos. Universidade Estadual de Campinas (UNICAMP)

3 BECKER, R.; WHEELER, E. L.; LORENZ, K.; STAFFORD, A. E.; GROSJEAN, O. K.; BETSCHRT, A. A.; SAUNDERS, R. M. A compositional study of Amaranth grain. Journal of Food Science, v.46, n.4, p. 1175-1180, 1981.

4 BEJOSANO, F.P.; CORKE, H. Protein quality evaluation of amaranthus wholemeal flours and protein concentrates. Journal of Science of Food and Agriculture, v.76, n.1, p.100-106, 1998.

5 BLIGH, E. C.; DYER, W. J. A rapid method of total lipid extraction and purification. Canadian Journal of Biochemistry and Physiology, v.37, p. 911-917, 1959.

6 BRESSANI, R.; GARCIA-VELA, L. A. Protein fractions in Amaranth grain and their chemical characterization. Journal of Agricultural and Food Chemistry, v.38, n.5, p. 1205-1209, 1990.

7 FIDANTSI, A.; DOXASTAKIS, G. Emulsifying and foaming properties of amaranth seed protein isolates. Colloids and Surfaces B: Biointerfaces, v.21, n.1, p.119-124, 2001.

8 IRVING, D. W.; BETSCHART, J. M.; SAUNDERS, R. M. Morphological studies on Amaranthus cruentus. Journal of Food Science, v.46, n.4, p.1170-1174, 1981.

9 JANE, J.; CHEN, L.; WANG, L.; MANINGANT, C.C. Preparation and properties of small-particle corn starch. Cereal Chemistry, v.69, p.280-283, 1992. 
10 LAEMMLI, U. K. Cleavage of structural proteins during the assembly of the head bacteriophage T4. Nature, London, v.227, p.680-685,1970.

11 LUQUEZ, N.G.; FERNÁNDEZ, S.; MUCCIARELLI, S.L. Concentrado protéico de Amaranthus cruentus. Métodos de extracción. Propriedades funcionales. Archivos Latinoamericanos de Nutricion, v. 46, n.2, p. 143-145, 1996.

12 MAHAN, L., ARLIN, K. Krause: alimentos, nutrição e dietoterapia. 8. ed. São Paulo: Editora Roca, 1995.

13 MARCÍLIO, R.; MAYA-FARFÁN, J.; CIACCO, C.F.; SPEHAR, C.R. Fracionamento do grão de Amaranthus cruentus brasileiro por moagem e suas características composicionais. Ciência e Tecnologia de Alimentos, v.23, n.3, p.511-516, 2003.

14 MARCONE, M. F.; KAKUDA, Y. A comparative study of the functional properties of amaranth and soybean globulin isolates. Nahrung, v. 43, n.6, p. 368-373, 1999.

15 MARTÍNEZ, E.N.; AÑÓN, M.C. Composition and structural characterization of Amaranth protein isolates. An eletrophoretic and calorimetric study. Journal of Agricultural and Food Chemistry, v.44, n. 9, p. 2523-2530, 1996.

16 MENDONZA, L.; BRESSANI, R. Nutritional and functional characteristics of extrusion-cooked amaranth flour. Cereal Chemistry, v.64, n.4, p.218-222, 1987.

17 MORR, C.V.; GERMAN, B.; KINSELLA, J.E.; REGENSTEIN, J.M.; VAN BUREN, J. P.; KILARA, A.; LEWIS, B.A.; MANGINO, M. E. A collaborative study to develop a standardized food protein solubility procedure. Journal of Food Science, v.50, n.6, p.1715-1718, 1985.

18 PAREDES-LÓPEZ, O.; MORA-ESCOBEDO, R.; ORDORICAFALOMIR, C. Isolation of Amaranth proteins. Lebensmittel Wissenchaft \& Technologie, v.21, n. 1, p. 59-61, 1988.

19 RADOSAVLJEVIC, M.; JANE, J.; JOHNSON, L.A. Isolation of amaranth starch by diluted alkaline-protease treatment. Cereal Chemistry, v.75, n.2, p.212-216, 1998.

20 SALCEDO-CHÁVEZ, B.; OSUNA-CASTRO, J.; GUEVARA-LARA, F.; 
DIMÍNGUESZ-DOMÍNGUEZ, J., PAREDES-LÓPEZ, O. Optimization of the isoelectric precipitation method to obtain protein isolates from Amaranth (Amaranthus cruentus) seeds. Journal of Agricultural and Food Chemistry, v. 50, n.23, p. 6515-6520, 2002.

21 SEGURA-NIETO, M.; VAZQUEZ-SANCHEZ, N.; RUBIOVELAZQUEZ, H.; OLGUIN-MARTINEZ, L.E.; RODRIGUEZ-NESTER, C.E.; HERRERA-ESTRELLA, L. Characterization of amaranth ( $A$. hypochondriacus L.) seed proteins. Journal of Agricultural and Food Chemistry, v.40, n.9, p.1553-1558, 1992.

22 SINGHAL, R.S.; KULKARNI, P.R. Amaranths: an underutilized resource. International Journal of Food Science and Technology, v.23, n. 2, p. 125-139, 1988.

23 SORIANO-SANTOS, J.; IWABUCHI, S.; FUJIMOTO, K. Solubility of Amaranth seed proteins in sodium sulphate and sodium chloride: the main factor in quantitative extraction for analysis. International Journal of Food Science and Technology, v.27, n.3, p. 337-346, 1992.

24 SORIANO-SANTOS, J.; CORDOBA-SALGADO, M. A. Evaluation de diferentes métodos de solubilización de nitrógeno para la obtención de concentrados proteínicos de semilla de Amaranto. Revista Española de Ciencia y Tecnología de Alimentos, v.35, n.2, p.161-177, 1995.

25 TEUTONICO, R.A.; KNORR, D. Amaranth: composition, properties and applications of a rediscovered food crop. Food Technology, 39, n.4, p. 49-60, 1985

26 WANG, C.R.; ZAIAS, J.F. Water retention and solubility of soy proteins and corn germ proteins in a model system. Journal of Food Science, 56, n. 2, p. 455-458, 1991.

\section{AGRADECIMENTOS}

Ao CNPq/PIBIC pela Bolsa de Iniciação Científica de Cathia Reis. As autoras também agradecem à Flavia Auler e ao Prof. Dr. Jaime Amaya-Farfán pela disponibilização das amostras de amaranto utilizadas no trabalho. 